\title{
La obra de Clemente Palma
}

En su juicio crítico de noviembre de I92I, firmado en Lima, acerca de Por senda propia, novela de Angélica Palma; dice José Gálvez lo siguiente:

"Don Ricardo Palma ha tenido, además de su obra, la incomparable suerte de dejar eñ sus hijos, Clemente y Angélica, dos muestras admirables de los blasones' intelectuales de su sangre. $\mathrm{Y}$ ambos, aunque Clemente no lo parezca a veces a la observación superficial, cada cual en su manera, en su amor a la narración y en su constructora tendencia imaginativa, lian hercdado mucho de las cualidades características del padre; $\ldots$ La ley de la herencia ha rendido en estos dos retoños verdaderos frutos de bendición".

También es intercsante el principio del prólogo de la primera edición de Cucntos malévolos (Barcelona, 1904), escrito por don Migutel de Unamuno:

"Mi estinado amigo: Acabo de leer los Cuentos malévolos, que ha tenido a bien darme a conocer antes de entregarlos al público. Me ha movido a leerlos pronto y con interés el saberle. a usted joven y el prestigio que para conmigo le presta el nombre de su padre, mi señor don Ricardo, de cuyo ingenio nos queda tan délcitoso dejo a todos los que le hemos leído. Quería ver si se corroboraba aquel dicho decidero: de tal palo tal asti- 
Ila, y todos los de la misma suerte, que no son pocos. $Y$ le aseguro que no se han quebrado mis esperanzas".

Nació el hijo del célebre cuentista en Lima, el 3 de diciembre de 1872 . Cursó la instrucción media, a partir de 1884 , los dos primeros años, en el Colegio de Maticorena y en el Colegio Nacional de Guadalupe, los cuatro restantes en el Colegio del doctor Pedro A. Labarthe. Ingresó en la Universidad de San Marcos en r892, y a la Facultad de Letras, graduándose de bachiller y de doctor de esta Facultad, en 1897. Luego se inscribió en la Facultad de Jurisprudencia $y$, después de haber cursado los cinco años de estudios, sólo se graduó de bachiller, haciendo su práctica jurídica en el estudio del doctor Javier Prado y Ugarteche.

Antes de escribir las disertaciones para la opción de los grados de bachiller y doctor en la Facultad de Letras, ya se habían impreso dos obras suyas: Excursión litcraria, (1894), serie de impresiones de lecturas de juventud, y El Perí, (r895), que el autor describió en $193^{8}$ como "librejo de finalidades pedagógicas con ligeros apuntes descriptivos de la geografía e historia del Perú, en torno de una ingenua acción novelesca".

El i2 de agosto de 1897 Clemente Palma leyó en la Facultad de Letras El porvenir de la raza, su tesis para optar el grado de Bachiller, que dedicó a los doctores Javier-Prado y Ugarteche y Pablo Patrón. Después de una introducción que trata de generalidades (por ejemplo, el reino humano, las leyes de la vida, el hombre como especie animal, las razas, los cruzamientos y el papel de los gobiernos), el autor observa que la voz de muchas razas grita en la sangre de cada individuo y que las que principalmente han constituido la población del Perú son las razas india, española, negra, china y también las mestizas.

Entonces cxamina la contribución de cada raza. $\Lambda$ umque la sangre india forma la base étnica de la entidad nacional, so encuentran en ella las siguicntes cualidades antipaticas la debi- 
lidad de carícter, la indolencia; la falta de aspiraciones, la astucia y la sutileza; características de las degeneradas. Además, el indio es refractario a la vida de las otras razas y la educación resulta impotente para variar la constitución mental de la raza. El aparente apogeo dè la raza en el período incásico fué obra de una estirpe inteligente que operó sobre la pasividad de la raza india. En efecto, el comunismo patriarcal era la única forma propia para una raza tan indolente. Anarquizado el poder central, el Imperio cayó y la unidad se disgregó. El coloniaje acentuó la inferioridad del indio y la Independencia no le levantó. Era imposible fundar en la raza india esperanzas de progreso.

La estirpe española fué formada por el cruzamiento del ibero con el latino. Es muy superior a la india, peró no ocupa, en las razas superiores, un sitio muy elevado. Sits características son la tenacidad, el valor, el amor a las formas, el fanatismo, una imaginación fogosa, un intelectualismo superficial, el espiritu de rebeldía y la inmóralidad política y privada..

El negro es una raza muy inferior. Es sana; pero en ella se cncuentran la senstialiclad, el odio a las razas superiores y el fanatismo.

También es inferior la raza china por la forma pueril, extravagante y artificiosa de su vida mental, por su inmovilidad, por su' egoísmo y por su absoluta-indolencia para el dolor humano.

Con todos estos clementos se lia formado la raza criolla. Las características que constituyen la tonalidad psíquica de esta raza mixta son la bondad de genio - acción del medio-, el espíritu artístico, la tendencia al desorden y a la anarquía y la vehemencia -acciones de la raza española-, la falta de carácter y el fanatisno - acciones de las tres razas - y la senstialidad - acción de las razas negra y española.

Al fin, habla Clemente Palma del poryenir de las razas y su terapéutica. La raza india pura es inepta para la civilización. Está condenada a cruzarse o a desaparecer y el empuje de la 
civilización la exterminará. El sistema yanqui es inadoptable. La raza negra desaparecerá, como entidad pura, por absorción. La raza china desaparecerá por inadaptación o por disposición. gubernativa. La única raza de porvenir es la criolla, o sean las. razas mixtas unificadas por la acción del medio. La falta de carácter imposibilita a esta raza para constituír una nacionalidad avanzada. El carácter no lo dan las leyes ni la educación. Por su condición de raza media, el criollo está en excelentes condi-: ciones para cruzarse con una raza enérgica, como la alcmana, que tiene grandes condiciones de intelectualismo, energía $y$ moralidad.

En el mismo año leyó Filosofía y arte, su tesis para optar el grado de doctor en la Facultad de Letras. Esta disertación provocó algún revuelo en el cuerpo docente de la Facultad. Se trata del ateísmo, del satanismo, de los poetas y artistas ateos y satánicos, y del androginismo.

En Barcelona, en 1904; se publicó la primera edición de sus Cuentos malévolos, para la cual don Miguel de Unamuno escribió ún prólogo. En París, en 1923, se publicó la segunda edición, considerablemente ampliada con un prólogo de Ventura García Calderón.

No deja el lector de admirarse de estos cuentos por su forma artística y su filosofía, que parece carecer a veces del idealismo cristiano. Por esto, Unamuno reprende al autor, por dos cuentos que se encuentran en la colección del modo siguiente:

"Es el uno el que usted intitula "El quinto cvangelio", y cuyo principio, se lo diré lisamente, arañó algo mis sentimientos cristianos. Jesús no pudo hablar de burla gruel de la Naturaleza, ni hay, digan lo que dijeren el desgraciado Nietzsche y otros de la misma frasca, nada más natural ni más humano, por lo tañto, que la religión de Jesús.

"En este cuento y en el que ha tenido usted la atención de dedicarme y titula : "El hijo pródigo", y del que le diré en seguida algo, encuentro un eco de juicios acerca del cristianismo y de la 
obra de Jesús que proceden de un muy imperfecto conocimiento de ellos; permítame que se lo diga".

En los otros cuentos abundan ejemplos de la misma filosofía; por ejemplo, "Los canastos",, el primer cuento, empieza del modo siguiente:

"Entre hacer un pequeño servicio que apenas deje huella en la memoria del beneficiado o un grave daño que le deje profundo recuerdo, elegid lo segundo. Os contaré lo que me sucedió una tarde de invierno con un pobre hombre llamado Vassielich":

Entonces nos refiere cómo un señor no da a entender a su vecino que los canastos de peces de éste están cayéndose del carro al agta, aunque ella significa el fracaso financiero del vecino. Se justifica, diciendo:

"Me encogí de hombros y proseguí mi camino, fumando mi pipa. Después de todo el sitio de los peces era el río y no los canasstos. He restablecido, pues, el equilibrio de la naturaleza".

En "Idealismos", alginas páginas del diario de un joven explican cómo él hizo morir a su novia por medio de la sugestión para que sus amores no perdiesen su idealismo. En "El últitimo fauno", el fauno rapta a una monja.

De una filosofía más idealista es "Parábola", donde un santo quiere aliviar los sufrimientos de los hombres y pide al Señor que suprima varios flagelos, pero los hombres quieren recobrarlos.

"¿Por qué- prosiguió el Salvador, sonriéndose. - Porque suprimiendo la enfermedad, la miseria y la lucha hemos creado, buen anciano, la inercia y el hastío; es decir, el mayor pecado y la mayor condenación.

"Y nuevamente los tres suprimidos flagelos cayeron sobre la tierra". 
"Los ojos de Lima" nos hace recordar Jettatura, novela de Théophile Gautier, ctando el teniente Jym les habla a sus compañeros del miedo que les tenía a los ojos de su novia, y cómo ésta se los arrancó para aliviarle de sus temores; pero se termina el cuento de un modo sorprendente: .

“.. De pronto, Jym soltó una carcajada burlona, que cayó como un enorme cascabel en medio de nuestras meditaciones.

"-iHombres de Dios! ¿Creéis que haya mujer alguna capaz del sacrificio que os he referido?: Si los ojos de una mujer os hacen daño, ¿ sabéis cómo lo remediará ella? Pues arrancándoos los vuestros para que no veáis los suyos. No, amigos míos, os he referido tuna historia inverosímil cuyo autor tengo el honor de presentaros.

"Y nos mostró, levantándola en alto, șu botellita de ajenjo, que parecía una solición concentrada de esmeraldas".

En I922, en Lima, apareció La cuestión de Tacna y Arica, artículos sobre materias internacionales, y en 1923, también en Lima, se publicó "Mors ex Vita", novela corta que se incliyó dos años más tarde en la publicación de sus cuentos Historictas malignas, en la misma ciudad. El autor explica este titulo del modo siguiente:

"El título que tiene este libro no es sino cuestión de impulso adquirido. Páginas de fantasía, que se hermanan a través de veinte años con las que con el título de Cuentos malévolos publiqué por primera vez en 1904 , en España, tenía que bautizar este libro con nombre de familia; por eso se titula Historietas malignas. Ya decía Unamuno, en el prólogo con que honró la primera edición de mis Cucntos, que no había encontrado, sino en pequeñas dosis, la decantada malevolencia de mis fantasías, y aunque mi voto no pueda pesar, tratándose de la calificación de materias de mi factura, declaro que tampoco en este libro la malignidad existe en forma alarmante, y me disgustaría que el lector no fuera de mi opinión, porque ello me probaría que en realidad soy más malo de lo que creo y tengo derecho de ser. 
Sea comó fuere, allá.va el librejo formado por narraciones que he podido pergeñar en los escasos momentos de vagar que me han permitido mis tareas de periodista, $y$ domeñando la pereza que para la desinteresada labor literaria hoy me domina. La última de las narraciones que aparece en este libro fué escrita en 1897 , y la he inchúdo como tin homenaje de mi madurez desilusionada y escéptica a mi juventud fervorosa y audaz".

\section{Al principio de "Mors ex Vita" dice el autor:}

"Yo estoy convencido de que esa llamada cicttcia de los espiritus está compuesta de un cincuenta por ciento de superchería, un cutarenta por ciento de fantasía y perturbación nerviosa; y. el resto de cosa desconocida; y me expreso así porque no encuentro otra manera de precisar, ainque imperfectamente, esas formas vagas con las que se manifiesta un misterio o se exterioriza la acción de una ley desconocida, que se percibe $o$ adivina en hechos que ni la superchería, ni el histerismo, ni la stgestión explican..$\therefore$ Después de lo que he referido, y que prueba la poca disposición dé mi espíritu para aceptar incondicionalmente los hechos maravillosos ¿querrán ustedes creer en la veracidad y buena fe con que haré el relato de una estupenda $y$ trígica aventura de Loredano? ¿Me creerán ustedes si afirmo, tajo mi palabra de honor, que no hay la menor exageración ni mentira en la relación del suceso marnvilloso en que fué actor principal Loredano, mi pobre amigo, que acaba de morir loco, suceso que no me ha sido reforido sino que he presenciado?"

Aunque Loredano no tenía más amigo intimo que Marcelo, dejó de verle en gran parte después que pusieron término a las experiencias espiritistas que habían tenido antes. El motivo de la alteración del carácter de Loredano fué el amor. Se había énamorado de Lodoiska, hija del embajador de Noruega, la cual pensaba volver a su país para casarse con un joven teniente de la marina de guerra de Noruega. Sin embargo, un mes antes de embarcarse; la señorita murió.

Se puso enfermo Loredano, y Marcelo se instaló en la casa 
de su amigo. Hizo venir a las tres tías del joven. Loredano se restableció y se dedicó a cultivar el recuerdo de la muterta. Al principio, Marcelo le acompañó en sus visitas al cementerio, pero muy pronto dejó de hacerlo.

Empezó a celebrar sesiones de espiritismo con sus tías. Su tía Hipólita resultó ser una medium. Marcelo y el doctor KKellermann se escondieron en la biblioteca para asistir a una de estas sesiones. Los dos testigos escuchaban lo que pasaba entre el espíritu y Loredano en el cansycorner del escritorio. $\mathrm{El}$ médico creyó presenciar las infamias de un incesto, y encendió la luz. "Huyó Loredano y los dos testigos encontraron muertas a las tres tías y huyeron. Loredano prendió fuego a su morada. Las tres tias no fueron salvadas y al sobrino lo condujeron al manicomio.

Por un primo suyo, que volvió después de haber pasado diez años en Europa, Marcelo supo que aquél había conocido al novio noruego de Lodoiska. Al llegar los restos de Lodoiska a su país, se abrió el ataúd. Se encontró la sortija de Loredano y al hacer el traslado del cadáver a stı nueva caja, una parte del vestido se rompió y dejó caer un pequeño feto de seis o siete meses.

"El hombre del cigarrillo" trata del suicidio de Satanás y termina con esta frase:

"Pero lo más extraño era que sólo había itilizado media cuerda y había dejado preparada con el resto de la cuerda otra horca con un papel en que decia : Para Dios".

"La aventura del hombre que no nació" trata de Aristipo Bruno, diputado, que se encuentra con un señor que se llama del mismo modo, se parece a él y es recibidó en vez de él. El diputado se da cuenta de que es el hombre que no nació y teme ser el hombre que no muere jamás.

"El carretón", la última narración y la de la juventud del autor, trata de un joven: a quien se cree muertó y es recogido 
por un carro mortuorio. Conversa con los muertos y al fin se despide de ellos. El cuento termina así:"

"Al despertar, ya muy avanzado el dia, me dolía fuertemente la cabeza y tenia en la boca un acre aliento de absintho".

X.Y.Z. (novela grotesca) fué publicada en Lima, en I 934 El autor la llama "un ejemplar de una novela de fantasía científica (?)". En su prólogo, el autor explica al lectór que al ser deportado a Santiago de Chile concurría en las noches a los teatros y se interesó por el cine hablado. Además, pensó:

"Ha más o menos cuarenta años; cuando el mundo entero se asombró con el maravilloso invento de Tomás Alva Edison, el registro de la patabra humana y de la música è tubos de cera, el conde Villiers de l'Isle $\Lambda$ dam escribió : ina romancesca fantasía en homenaje al prodigioso invento, La Eva futura, la novela del fonógráfo. .... Cuando el arte y la industria cinematográficos alcanzaron mayor auge pensaba que esta deleitosa y espiritual conquista de la ciencia, que lo era tanto o más que el fonógrafo, merecía tener también su novela. Sólo qué ya el conde Villiers había muerto y en más de un momento tuve la petulante tentación de intèntar escribirla con olvido de mi condición de escritorzuelo pobre diablo".

Al principio, no cedió a la tentación por creer que: "un romance sobre el cine exige el conocimiento del medio en qute viven las 'estrellas', de su psicología, y siquiera haber visitado la metrópoli del cine, Hollywood"; pero, al fin, se decidió a cscribir el libro como su último engendro imaginativo: "Y asi una mañana tibia de marzo comencé este romance grotesco de marionetas $y$, con intervalos más o menos largos, lo terminé uṇa mañana lluviosa de junio".

Se trata de las experiencias de Rolland Poe, natural de Los Angeles y estudiante de la universidad de esa ciudad. Este joven convertía toda la fenomenología de las fuerzás físicas en ecua- 
ciones. Por eso, sus compañeros le apodaron con el remoquete de doctor $X y z$. Se graduó de ingeniero, "leyendo en la universidad una brillante tesis que fué muy celebrada y discutida en los circulos científicos... y se le consideraba como el futuro heredero de Edison; no faltaban quiénes le atribuian major preparación técnica y mentalidad más vigorosa que la del eminente padre del fonógrafo".

Después, una noche, en uno de sus talleres de Miami, hizo pasar una cinta sonora y meditó sobre la posibilidad de resolver el problema de la materialización de esas figuras visibles y aitdibles pero intangibles y de hacer intervenir el sentido del tacto. Alquiló una isla y, después de muchos experimentos, realizó sus proyectos, pero todavía tenía que reanudar la vida de sus criaturas de vez en cuando. Unos artistas de Hollywood visitaron la isla, descubrieron sus muñecas, y contra la oposición de Poe, las llevaron a Hollywood para exhibirlas: Poe llegó al teatro la noche de la representación. Se terminó la vida de las muñecas durante la representación, y se mató su creador.

El año siguiente el autor publicó en Lima "Había una vez un hombre", artículos de polémica política, y un estudio critico: "Don Alonso Enríquez de Guzmán y el primer poema sobre la conquista". En la misma ciudad, en 1938, se publicó Crónicas político-doméstico-taurinas de corrales, selección de humorísticos artículos políticos publicados en "Variedades"; con prólogo del autor, epílogo de José Gálvez, $y$ un glosario del argot limeño: : En octubré de este mismó año, se hízo secretario de la Comisión Nacional de Cooperación Intelectual.

De su périodismo, dicc Clemente Palma:

"Mi producción, como la de todo periodista de larga actuación, es bastante crecida y contenida en más de mil editoriales de Variedades, Prisma, Jlustración Peruana, en mis Notas de Artes y Letras, en el chirigoteo crítico de malos poetas que formaba la sección de Correo Franco de la primera, colaboraciones en el Mercurio de Santiago y en La Nación de Buenos Aires 
durante mi destierro en Chile, discursos, conferencias, prólogos de libros, etc. Algunos de los muchos cuentos que escribí y publiqué en diarios y revistas del Perú y en el extranjero, tales como Las queridas de humo, La redención, Diatriba bíblica y algunos más, aparecerán, si la cabalgadura vital no me despide a tierra antes, cuando termine de recopilarlos".

Al dar contestación a la pregunta sobre cuál de sus obras, a su juicio, es de mayor importancia, dice el autor:

"Para mí todas mis obras tienen la importancia propia del momento psicológico o de la zona ideológica de mi espiritu cuando las produje. Se asegura que soy un imaginativo, y si acato esta calificación lógićamente debo decirle que en los Cucntos malévolos es donde con mayor libertad se ha movido mi fantasia".

$Y$, al final, explica la variedad de los asuntos de su obra literaria del modo siguiente:

"...nuncá en mi labor literaria me he sometido a lineamientos trascendentes. Todas las corrientes estéticas y todas las técnicas literarias en boga antes y hoy encuentran fácil y simpática penetración en mi espíritu, porque todas ellas son modalidades de vibración imaginativa y traducen la inquietud y dinamismo en la marcha hacia el ideal, siempre lejano e inaccesible, pero que nos parece siempre más cerca. Esta ilusión es la que estimula. el a fanoso anhelo de las generaciones jóvenes para captarla. Pero como he creido siempre que por todos los rumbos de la rosa náutica literaria se va a los horizontes del ideal, jamás me he preocupado de informar mi viaje en tesis y derroteros".

\author{
VIRGIL $A$. WARREN, \\ Carson-Neroman Collegc.
}


